Journal of Accident and Emergency Medicine 1995 12, 210-211

\title{
Traumatic dissection of the internal carotid artery resulting in dense hemiplegia
}

\author{
J.B. SHESHGIRI ${ }^{1} \&$ N. MULLATTI ${ }^{2}$
}

'Accident and Emergency Department, and ${ }^{2}$ Department of Neurosciences, Frenchay Hospital, Frenchay, Bristol, UK

\section{INTRODUCTION}

Hemiplegia in a fit young person is a rare presentation to the accident and emergency (A\&E) department. We present an unusual case of posttraumatic hemiplegia.

Keywords: angiography, carotid dissection, hemiplegia, trauma.

\section{CASE REPORT}

A 23-year-old female university student was brought to the A\&E department, supported by her friends who were concerned about her strange behaviour. She had been out the previous night with friends and was attacked by a person who punched and kicked her to the ground. The exact mechanism of injury was not known, but there may have been a throttling attempt. There was no history of loss of consciousness. She was helped back to her shared accommodation and put into bed by friends. The following morning they noticed that she would not speak, had a vacant stare and had been incontinent of urine and faeces in bed.

Examination revealed a fully conscious but aphasic patient with deviation of the left side of the mouth and drooling of saliva. She had a dense right hemiplegia. There was no evidence of external injury and no carotid bruits were present. Cervical spine and skull radiographs were normal, and initial CT scan of the head showed no abnormalities. Carotid angiography revealed dissection at the origin of the left internal carotid artery (ICA) with complete occlusion. A CT scan 3 days later showed left cerebral infarction attributed to dissection of the left ICA.

Treatment was commenced with anticoagulation and further supportive therapy including rehabilitation, speech therapy for predominantly expressive dysphasia and physiotherapy for right- sided weakness.

Three months later the patient can speak but she cannot read or write any sentences. There is still no function in the right arm, but some function in the right leg, and she can walk with the aid of a stick. She will not be able to return to university at present.

\section{DISCUSSION}

Carotid artery dissection has been increasingly reported in recent years. ${ }^{1-3}$ Dissection of the ICA may be either spontaneous or traumatic. Traumatic dissection usually follows blunt injury, which may be trivial, e.g. simple falls or minor knocks to the head, especially in the elderly with atherosclerotic carotid arteries.

Damage to the ICA in blunt trauma is relatively uncommon, despite the high frequency of cervical trauma seen in the A\&E departments. ${ }^{1}$ Trauma can be direct, from a blow, or indirect. Indirect forces cause a rotational stretch of the artery, usually against the transverse process of the $\mathrm{C} 1$ vertebra, leading to rupture.

Typically there is initial ipsilateral headache and neck pain followed by a lucid interval of a few hours to a few days, depending on the time taken by the dissection or thrombus to progress and occlude the artery. This is followed by neurological deficit, often in the form of a stroke. Oculosympathetic palsy (partial ptosis, enophthalmos, meiosis and anhidrosis) is common, and is often the first clue suggesting dissection. ${ }^{2-3}$ Treatment is either thrombectomy with intimal flap repair, or a bypass graft, depending on the site of occlusion and dissection.

In this patient, in view of the complete occlusion of the artery, surgery was not feasible and anticoagulation was carried out in order to prevent progression of the thrombus. 
The prognosis is worse for traumatic dissection than for spontaneous dissection, with reasonable recovery observed in only $50-60 \%$ of cases.

\section{CONCLUSIONS}

Blunt head and neck trauma with a neurological deficit, in the absence of cervical spine injury or intracranial bleeding, should arouse the suspicion of carotid artery dissection, especially when associated with ipsilateral neck pain and Horner's syndrome (oculosympathetic palsy). The trauma need be only trivial.
CT brain scan in the early stages usually reveals no abnormality. Cerebral angiography should then be undertaken in order to confirm the diagnosis.

\section{REFERENCES}

1. Mokri B. Piepgras D.G. \& Wayne Houser O. (1988) Traumatic dissections of the extracranial carotid artery. Journal of Neurosurgery 68, 189-197.

2. Hart R.G. \& Easton J.D. (1983) Dissection of cervical and cerebral arteries. Neurologic Clinics 1, 155-182.

3. Bogousslavsky J., Regli F. \& Despland P.A. (1987) Spontaneous carotid artery dissection with acuteh stroke. Archives of Neurology 44, 137-140. 